\title{
Allogeneic Natural Killer Cell Line NK-92
}

National Cancer Institute

\section{Source}

National Cancer Institute. Allogeneic Natural Killer Cell Line NK-92. NCI Thesaurus. Code C117231.

A proprietary, human cytotoxic cell line composed of allogeneic, activated, interleukin-2 (IL-2) dependent-natural killer cells derived from a 50-year old male patient with rapidly progressive non-Hodgkin's lymphoma, with potential antineoplastic activity. As NK-92 cells are devoid of killer inhibitory receptors (KIRs; also called killer cell immunog lobulin-like receptors), which are negative regulators of NK cell activity, cancer cells are unable to suppress the cancer cell killing ability of the NK-92 cells. Upon infusion of the allogeneic NK cell line NK-92, the NKs recognize and bind to tumor cells. This leads to the secretion and release of perforins, granzymes, cytokines and chemokines, which results in cancer cell lysis and apoptosis. In addition, NK-92 cells express high affinity Fc receptors, which bind to therapeutic antibodies; therefore, this agent can enhance antibody dependent cellular cytotoxicity (ADCC) of co-administered therapeutic antibodies. 